\section{New addition}

Microbrush has introduced Microbrush X, the newest member of the Applicators family.

It is designed with a thinner, longer brush tip to simplify application for procedures involving confined spaces such as bonding posts, inlay, onlay cementation and sub-gingival application.

The shorter stiffer brush fibres hold a fraction of a drop of material for precise placement and allow for scrubbing.

Microbrush X was tested by dentists using a wide array of dental materials and was found to be diverse in the types of procedures in which it could be used. For ease of use the applicator bends firmly to 90 degrees and the kit includes a cartridge of 100 applicators and a Microbrush X dispenser.

Reader response number 55

\section{Setting standards}

Henry Schein had added the Point4 Flowable from Kerr to its range and claims it sets a new standard in flowable composite technology.

By combining the very small particles a lower volume of filler enables it to flow. Features include controllable viscosity, ultra-high polish, high aesthetics and a small particle size. It is suitable for class I, II and $\mathrm{V}$ cavities, as a pit and fissure sealant, as a preparation liner or temporary crown repair, a composite or porcelain repair and as a veneer cement.

Reader response number 56

\section{Polish and go}

A new polishing system has been launched by Dentsply which uses a one-step technique to create a high glass-like finish on all restorations. PoGo can be used to polish all composites, microfills, flowables and micro hybrids in one step. The disc offers polishing without any messy plates and is less time consuming than other polishing systems.

Reader response number 57

\title{
Complete restorative system from Dentsply
}

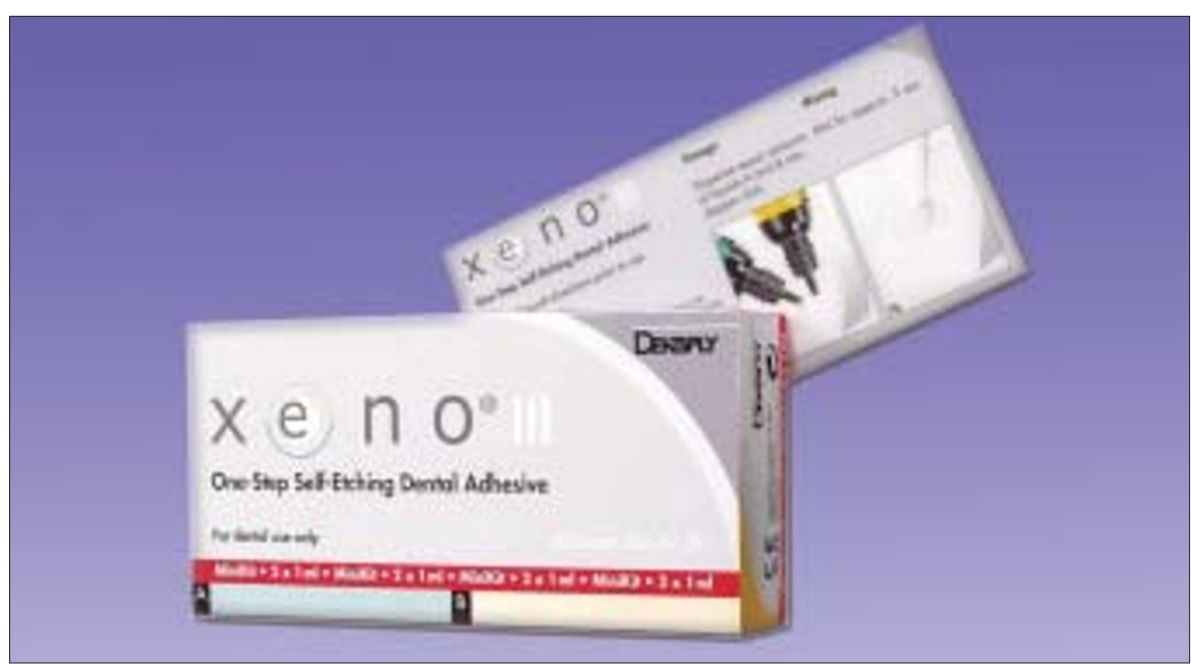

A complete restorative system is available from Dentsply, enabling GDPs to use products suitable for their exact dental requirements.

The Ash Hi-Di Diamond range offers a wide variety of patterns to aid dentists. They are well balanced to minimise vibration and hence prolong a handpiece's life.

PrimettBond is a bonding agent which gives extremely high bond strength. It has a simple application procedure with a onecoat technique. With the recently launched Xeno III (pictured above) dentists now have the choice of using self-etching dental adhesive during the bonding procedure.

It requires no separate etching and rinsing step and can be used for all cavity classes, light cured composites, ormocers and compomers.

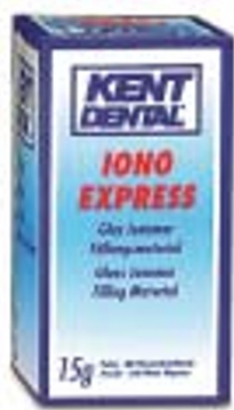

Dytract Flow has been specifically designed for minimal invasive dentistry, it offers flowable consistence to repair small cavities. It is easily extruded from the syringe and stops flowing quickly after it is applied. It therefore retains its shape and does not spill over cavity margins.

During the filling stage, Dentsply Ash instruments are available in traditional stainless steel, ceramic and new silicone handles.

Spectrum is a sub-micron hybrid composite for the restoration of both anterior and posterior teeth. It is ideal for use with deTrey Conditioner 36 etch gel and Prime \& Bond NT. Lastly PoGo allows quick and easy means of polishing the final composite to a high lustre.

Reader response number $\mathbf{5 8}$

\section{Fast-acting filler}

The Ionoexpress Fill glass ionomer is a water mixable powder-liquid system that has a working time of two and a half minutes and a setting time of three to five minutes. It includes Vita shades, a 25\% bigger pack size, easy mixing with smaller size particles to ensure a better outline seal for the cement and a smoother surface for the filling material.

Reader response number 59 


\section{Articulator systems}

Benchmark has established and standardised articulators throughout all their laboratories, complimenting their client base with the popular Denar \& Kavo articulator systems.

Both systems are immensely flexible and easy to use and simulate natural jaw movements as well as being widely used in postgraduate teaching centres throughout the UK for occlusion an advanced restorative procedures.

Features include simulation of the natural jaw movements for built in prosthesis design and accurate interchange from instrument to instrument.

For example, a case mounted on one Protar articulator (using the split cast) may be remounted on any other Protar articulator with total accuracy. This way the dentist can check the job with their

\section{Life-like aesthetics}

Esthet-X from Dentsply has been launched in answer to the increasing demand for aesthetic restorations.

It combines life-like aesthetics with one of the toughest materials on the market. It offers the choice of either a quick standard two-layer technique or a detailed threelayer technique and is formulated to offer easy non-sticky handling with excellent sculpability.

It is suitable for all classes of restoration and can be finished to a glass-like smoothness with Enhance Polishing System. Reader response number 61

\section{Improving bonding}

Launched earlier this year iBond, the first ever '7th' generation adhesive simplifies the bonding process by eliminating the need for conditioning of dentine and enamel with acid. The product is the only self-etching, self-priming, single bottle combined adhesive and desensitiser currently available.

It is suitable for bonding direct composite and amalgam restorations as well as indirect composite, polyglass and porcelain restorations. Applied in three layers and light cured, the system eliminates the uncertainty of mixing and greatly simplifies the adhesive procedure.

It is simpler than multi-component selfetching bonding systems. Its bond strength to dentine is in the region of $18-25 \mathrm{MPa}$, regardless of the moisture or lack of moisture on the prepared surfaces. The material provides similar adhesion to both prepared and unprepared enamel and also adheres to ceramic and metal.

Reader response number 62

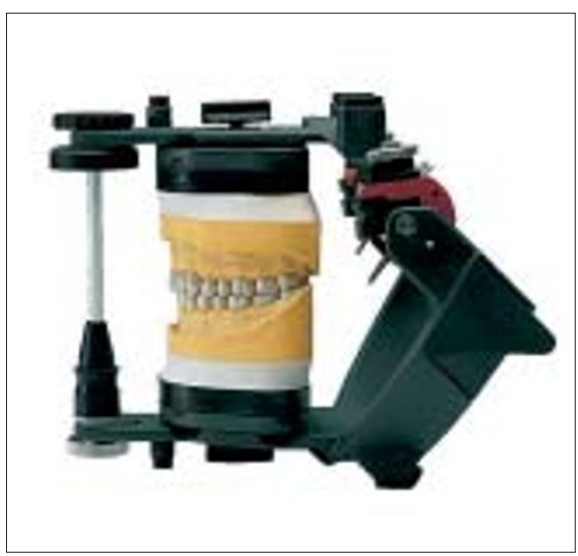

own articulator.

It is a durable and long lasting piece of equipment resulting in low maintenance costs. The KaVo Protar can be used in conjunction with most other popular facebow systems.

\section{Reader response number 60}

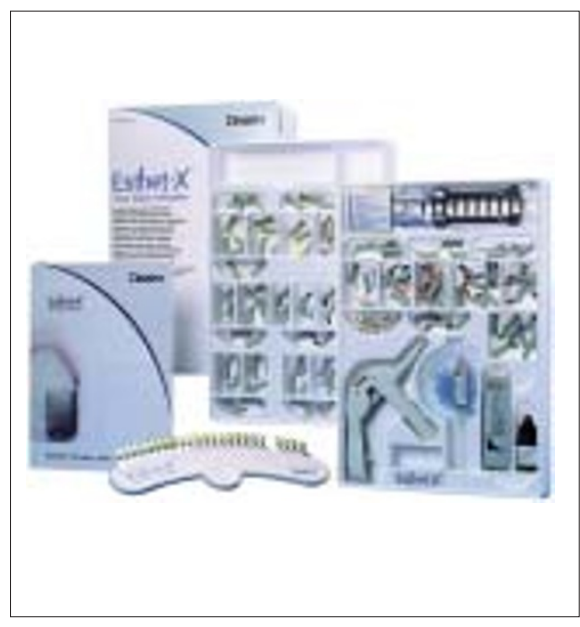

\section{Sensitive teeth}

Desensitising product SuperSeal eliminates sensitivity from restorative procedures by causing the formation of calcium oxalate crystals down in the dentine tubules as much as ten microns into the tubal structure. This results in long lasting desensitisation that can last for years from a single application.

It can also be used to prevent sensitivity from any restorative procedure without any negative effects on bond strength.

\section{Reader response number 63}

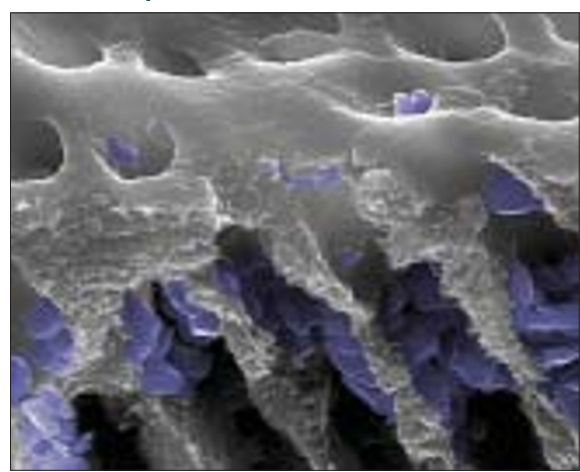

